\title{
Library Facilities and Practices in Colleges of Veterinary Medicine
}

\author{
BY GEORGE H. FADENRECHT
}

LitTLE LITERATURE exists that can be used in a comparative study of library facilities for the study of veterinary medicine. In order to develop a plan for such facilities at Kansas State University a survey was made of current practices in colleges of veterinary medicine in the United States.

To obtain this information a questionnaire was sent to colleges of veterinary medicine. One page in length, the questionnaire was brief enough so that a high percentage of returns could be expected. Sixteen of eighteen had been returned by the time of this writing. The date of the questionnaire covered the year 1962-63 with one exception for 1963-64. A short supplemental questionnaire was sent later, with fifteen returns.

The American Veterinary Medical Association states that, "adequate library facilities are essential to a sound program of veterinary medical education and research. The library should be established as a part of the veterinary medical school; it should be well housed, conveniently located, and available for the use of students and faculty at all reasonable hours. It should be administered by a professionally trained or experienced librarian and should be adequately sustained both for operation and for the purchase of current periodical and other accessories of veterinary medical importance."1 According to the survey made by Verner L. Johnson and Ernest C. Stove in 1959, "on some of the college campuses the veterinary area is situated physically

${ }^{1}$ American Veterinary Medical Association, "Essentials of an Acceptable Veterinary School," Directory (Chicago: AVMA, 1962), p.82.
Mr. Fadenrecht is Director of Libraries in Central Washington State College, Ellenburg.

close to the all-college library. Thus, the all-college library may serve the spirit of the AVMA requirement, although the letter of the requirement is not satisfied." 2

Of the sixteen libraries responding to the questionnaire, one, Iowa State University, has its veterinary literature completely integrated and housed in the central library. Thus the data that will appear hereafter will exclude Iowa State University.

Of the fifteen libraries under consideration, thirteen are placed in the administrative structure under the director of libraries, and two directly under the dean of the veterinary college. With the exception of one, all libraries are located in one of the buildings of the veterinary college. One other college, Washington State, is in the process of constructing a separate veterinary medical library building.

Of the veterinary medical librarians, eleven are professionally trained in library science, and four are clerks, two of whom have considerable library experience.

The collections of the libraries vary in size from a high of thirty-five thousand and five hundred volumes to a low of five hundred. There is a median of 10,143 and an average of 11,062 volumes. Figures for the number of volumes added during the year were available from only thirteen libraries, with a high of two thou-

\footnotetext{
${ }^{2}$ Library Facilities in Colleges of Veterinary Medicine (Pullman, Washington; 1959), mimeo.
} 
sand and a low of one hundred and fifty, a median of eight hundred, and an average of nine hundred and ninety-five. In both of the above categories it appears that many were estimates. In number of volumes held, four were to the nearest hundred and seven to the nearest thousand. Only three reported to the exact unit. In periodical titles received the figures given appear more exact. With fourteen reporting, the high for periodical titles received was six hundred and fiftyseven and the low fifty, with a median of three hundred and thirteen and an average of three hundred and twelve. (See Figure 3.)

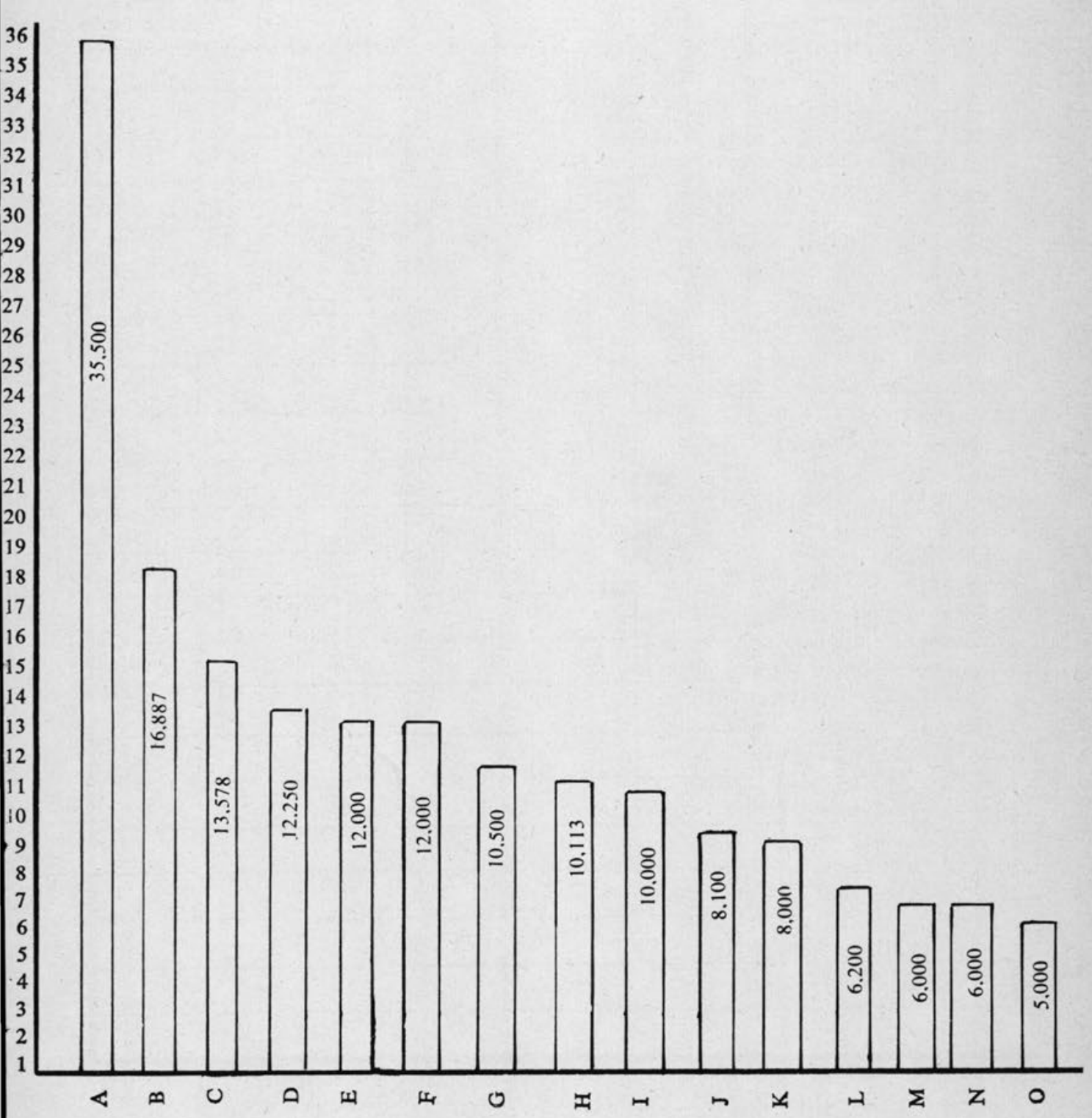

FIG. 1-Holdings in number of volumes. 


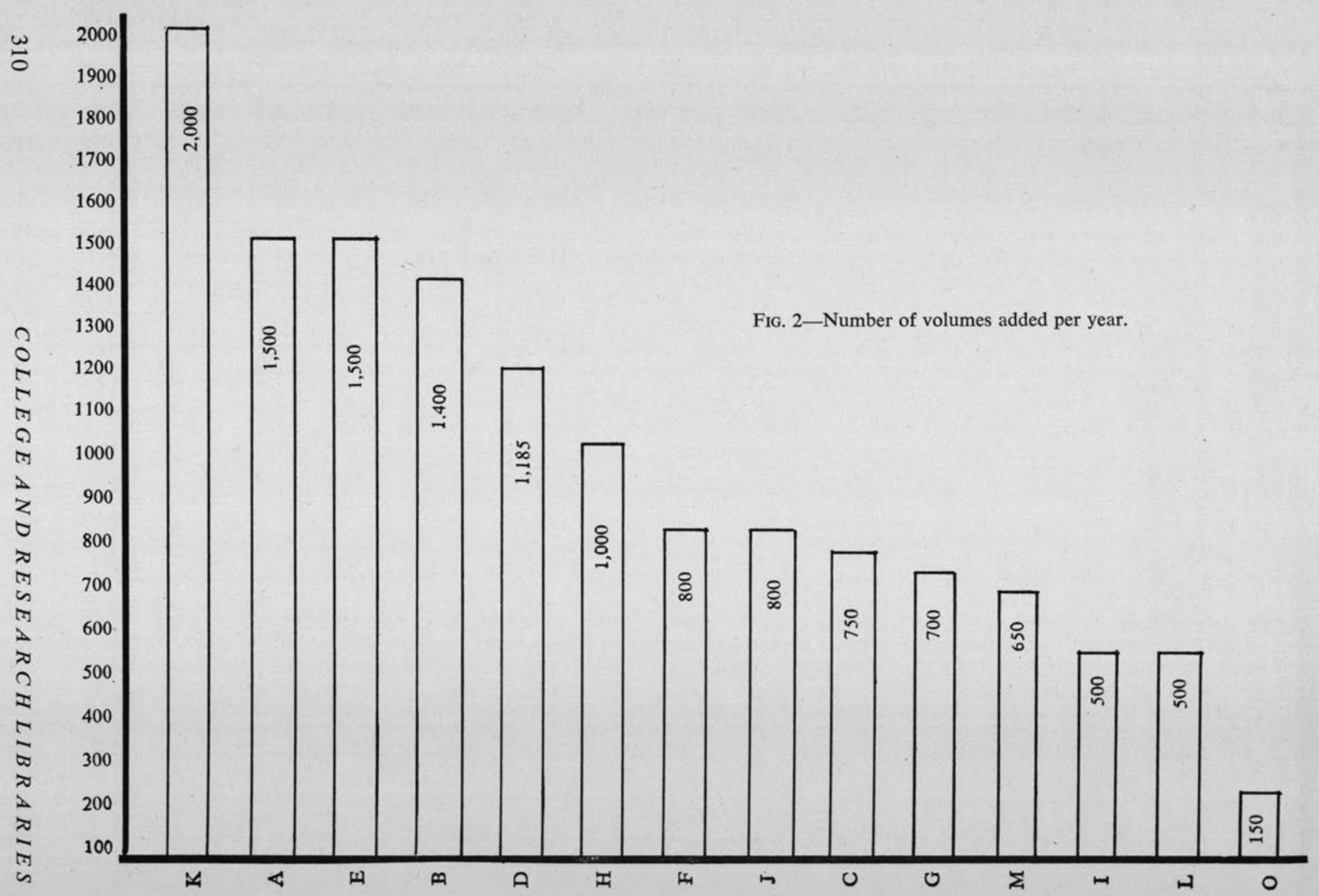




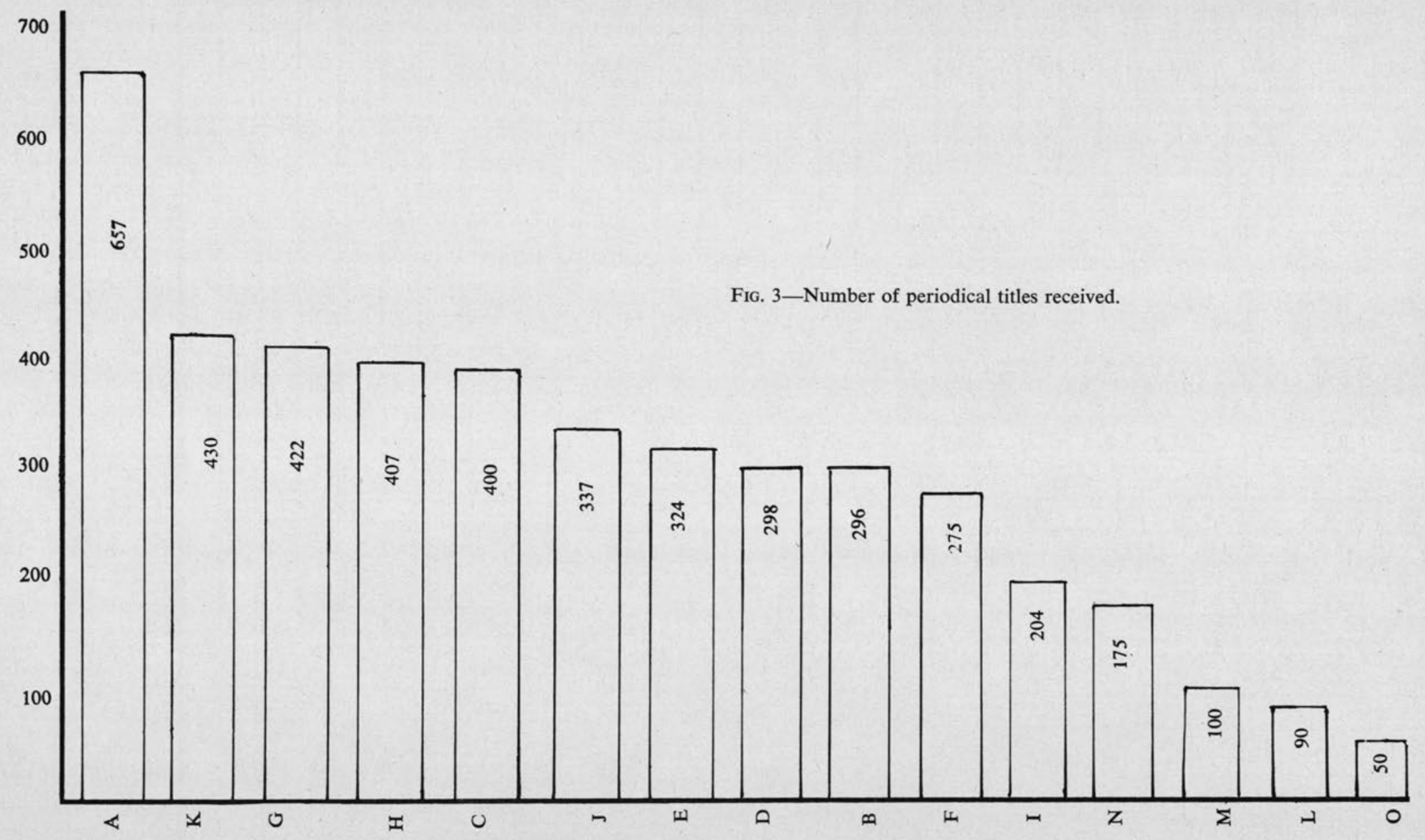




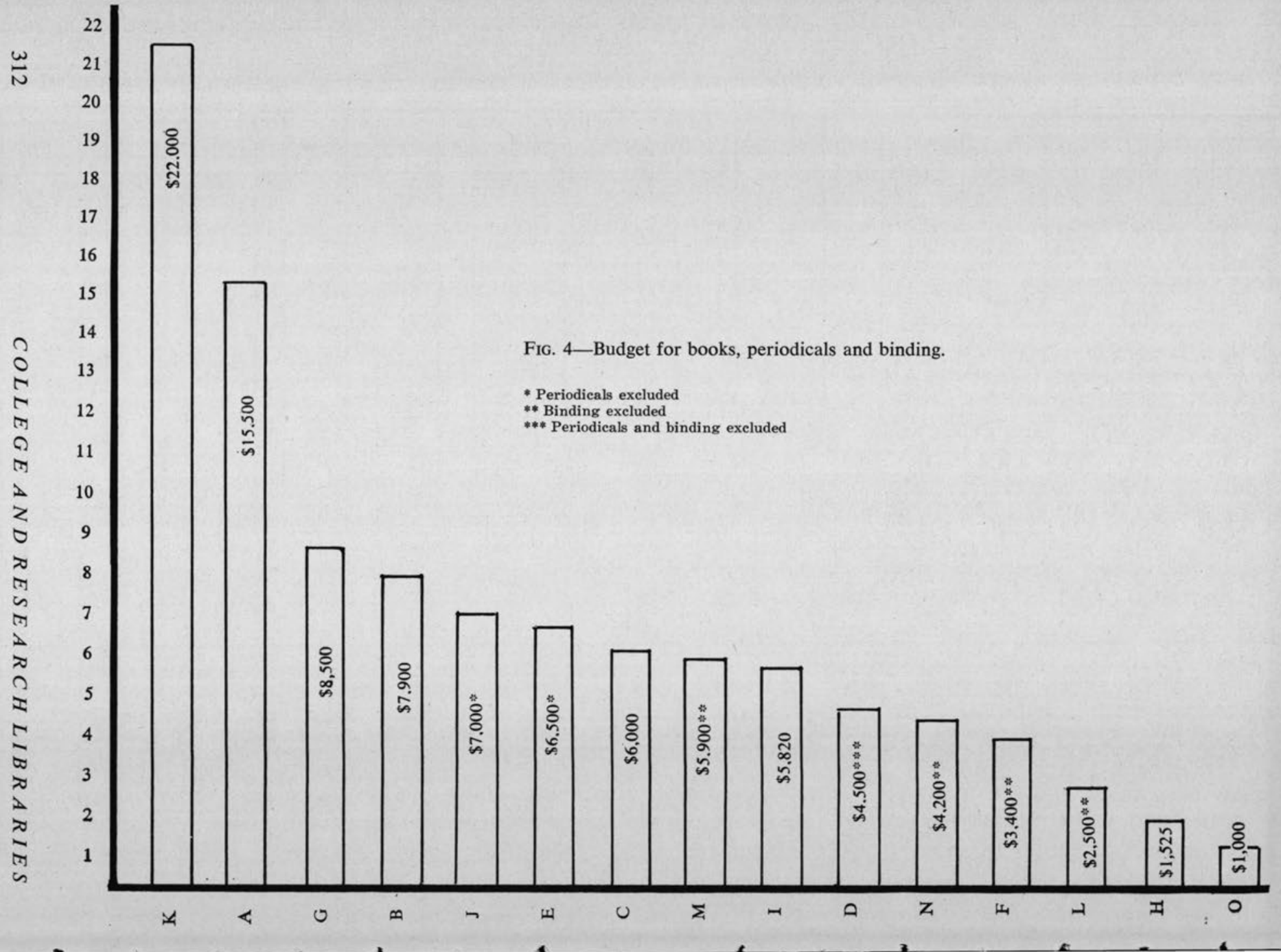




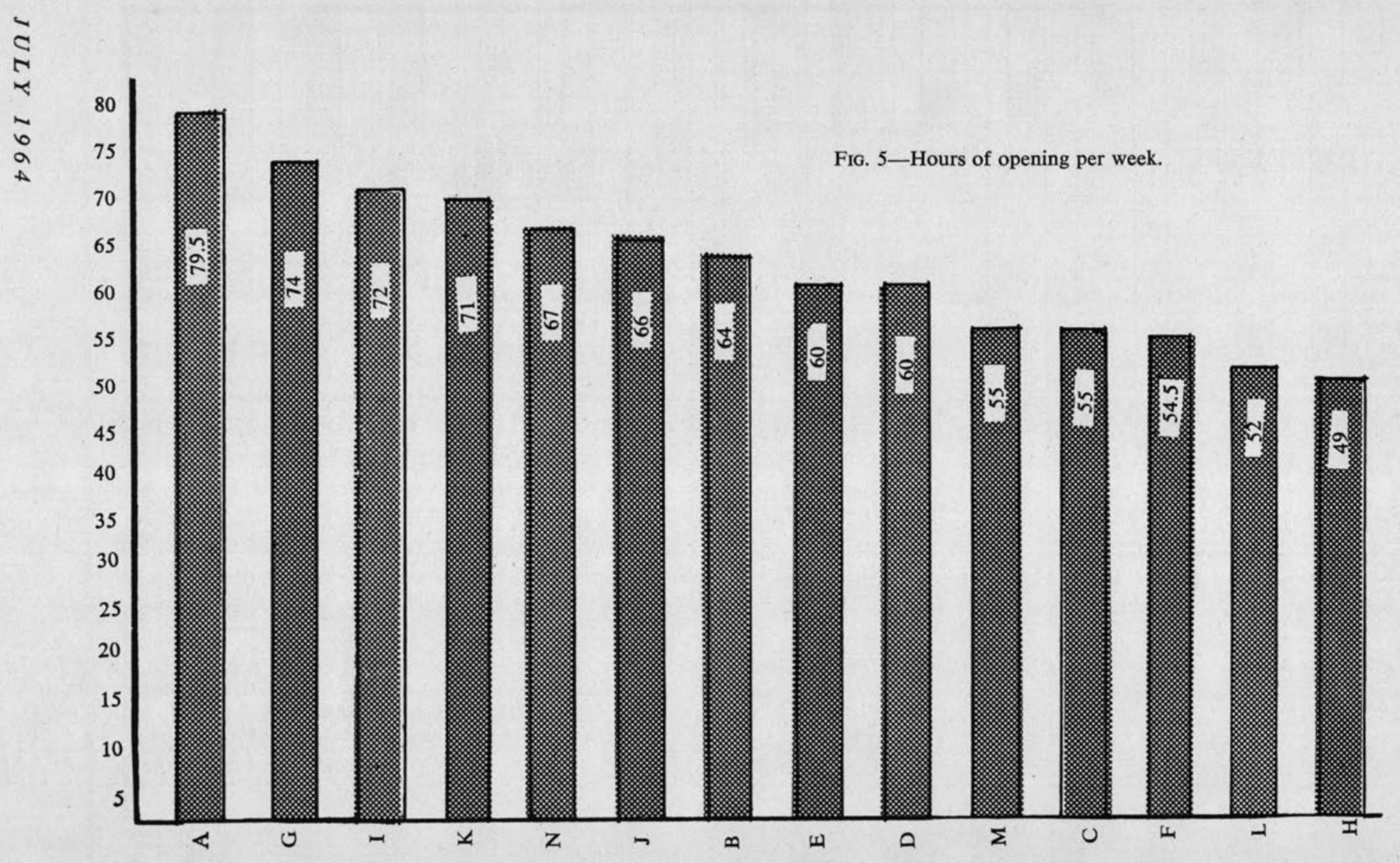

w 


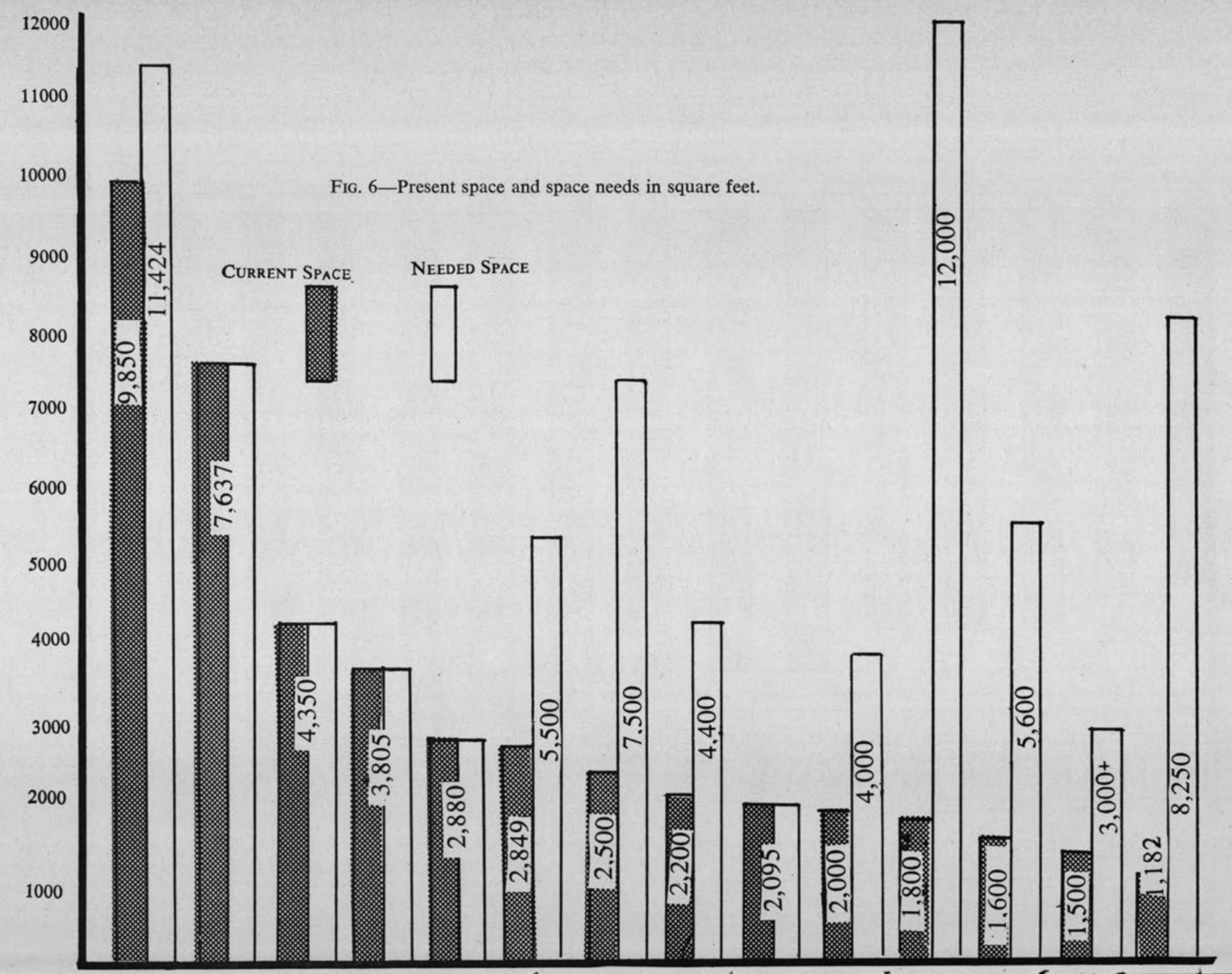




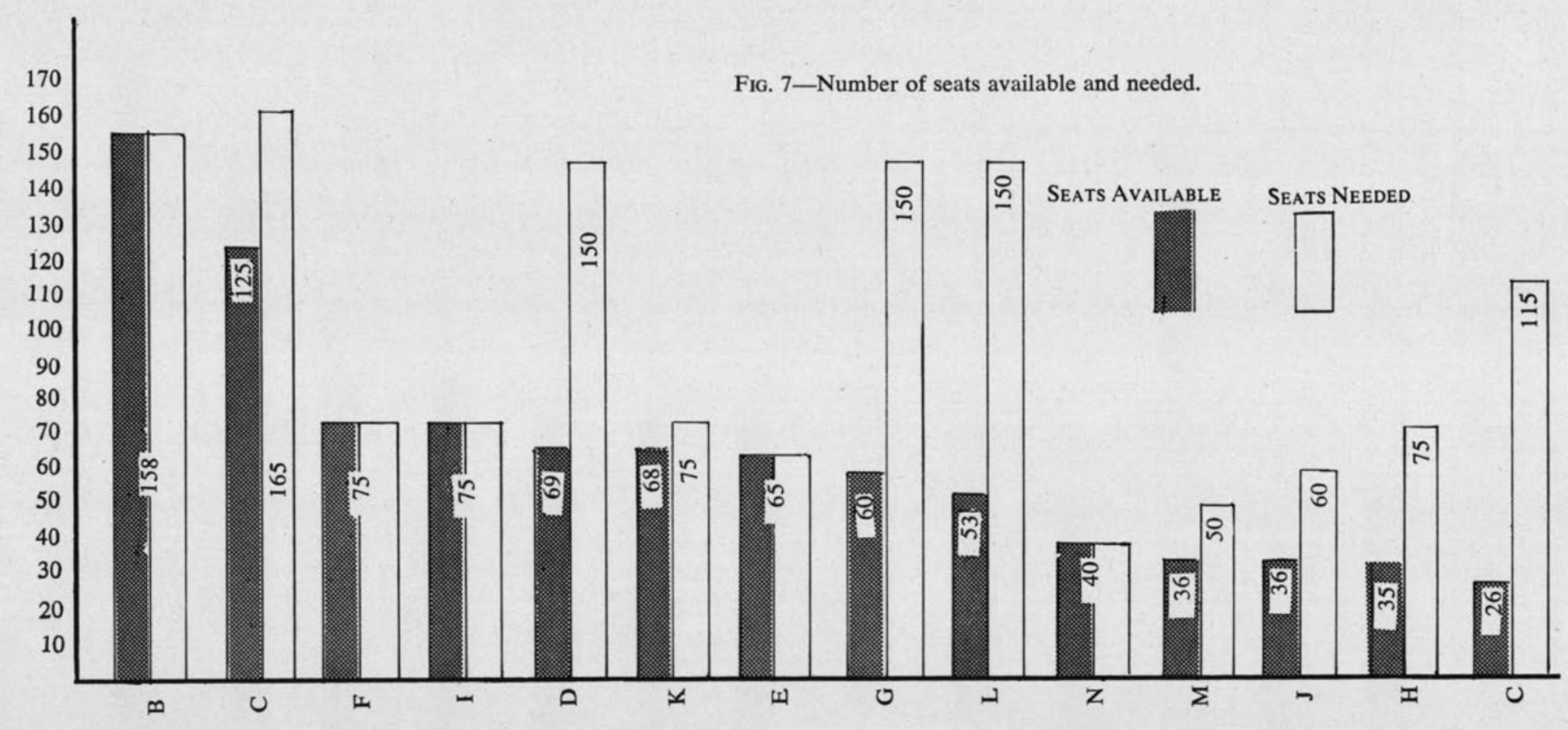


In trying to divide the budget into money for books, for periodical subscriptions, and for binding, one runs into the difficulties of combined figures in books and periodicals or of the absorption of all subscriptions into the general library subscription budget. The binding budget generally was part of the general library binding budget. Of fifteen libraries, only five could give specific figures budgeted for periodical subscriptions and only six for binding budgets, thus making medians or averages impossible. Of these fifteen libraries, twelve had specific figures for books, with a high of $\$ 12,500$ and a low of $\$ 1,000$, a median of $\$ 4,300$, and an average of $\$ 5,033$. One figure was for the 1963-64 fiscal year instead of the 1962-63 year. The three libraries combining books and periodicals in the same figures reported amounts of $\$ 4,500$, $\$ 4,200$, and $\$ 2,500$. (See Figure 4, which combines budgets for books, periodicals, and binding.)

In fourteen institutions the veterinary library materials are ordered by the general library, and one library ordered directly. In fourteen, the library materials are cataloged by the general library, and the general library catalog contains cards for this collection. One veterinary medical library is now being recataloged, and cards are being added to the general library catalog.

The length of the lending period for books varied. Nine out of fifteen libraries had a lending period of two weeks, three of four weeks, and one each of three weeks, one week, and overnight. One two-week library lent books to faculty for a semester, and one four-week library allowed four weeks to graduate students and faculty, and three weeks to undergraduates. Another four-week library restricted new books to one week.

There was even greater variation in the lending period for periodicals. One library lent periodicals for one to three weeks, three for one week, and one re- stricted the one-week loan to periodicals five years old and over. At the other extreme, two libraries lent journals only overnight, and two did not lend them for use outside the library. One library limited journals less than five years old to overnight. Another limited journals to three days except to undergraduates, who were allowed library use only. One library restricted unbound materials to room use, but lent bound journals for two weeks to faculty and three days to graduate students. Still another lent to faculty and graduate students for twenty-four hours, restricting undergraduates to library use, and one other lent journals to undergraduate students overnight, to graduate students for three days, and to faculty for three days to two weeks.

Fourteen libraries responded to the question on space currently in use. The high in square feet was 9,850 , the low was 1,182 , with an average of 3,303 , and a median of 2,350 . Nine stated that more space was needed while four said their current space was adequate. One library said it needed twelve thousand square feet, while another needed twice its present space of fifteen hundred square feet. The response to the needed space for books varied in form, some giving square feet, some linear feet, and others number of volumes. An estimate would place the need for book space between fifteen thousand to thirty thousand volumes, excluding the one library which had over thirty-five thousand volumes.

Seating space currently available varied from a high of 158 seats to a low of 26 , with a median of 62.5 and an average of 72.5 seats. The required seating space varied from a high of 165 seats to a low of 40 , with an average of 96.6 seats. (See Figure 7.)

The enrollment of a college often plays an important role in determining the amount of space needed, but this is not borne out in this survey. One of the (Continued on page 395 ) 
the Late Nineteenth and Twentieth Centuries" by Arthur H. Minters, art dealer. At the meeting of the Agricultural and Biological Sciences Subsection, Charles W. Schilling, George Washington University, described the work in the pilot program of the Biological Sciences Communication Project on the compilation of an extensive body of information dealing with aquatic biology. Dr. Martin Cummings, National Library of Medicine, showed a film, "The Medlars Story" to illustrate his discussion of the theme of library service to users at the research level. The Law and Political Science Subsection met jointly with the American Association of Law Libraries to hear about the Library of Congress classification for Anglo-American law. The Slavic and
East European Subsection heard of some experiences in building Slavic research collections.

The Standards committee held an open meeting to provide an opportunity for junior college librarians and officials and representatives of the American Association of Junior Colleges to discuss the strengths and weaknesses of the ALA Standards for Junior College Libraries. The Committee on Cooperation with Educational and Professional Organizations gathered with St. Louis architects to compare notes on mutual problems. Members of the Urban University Libraries Committee and guests heard a report by Bernard Kreissman on cooperative projects in New York metropolitan libraries.

\section{VETERINARY MEDICINE . . .}

(Continued from page s16)

larger colleges required the smallest number of seats and number of volumes. It was not determined whether the general library provided additional facilities. Some of the smaller colleges, however, were much more ambitious in their stated needs, though it should be said that the two institutions with the highest enrollments did require the largest facilities.

In addition to the fact that of fourteen libraries all but one served clientele from outside the veterinary college as well as their own, the final point determined was that the hours of service per week were less than for general libraries. The greatest number of hours open per week was 79.5 and the lowest 49 , with a median of 62 and an average of 62.8 .

A question may be raised concerning the amount of related and supporting material that is part of the general library collection and its relationship to the veterinary collection. The assumption that much material of this kind does exist in either the main or another branch library is supported by the fact that at Kansas State University the veterinary library collection consists primarily of gifts from friends of the veterinary college and books purchased from contributions from alumni. Almost all purchases from general library funds are housed in the general library rather than in the veterinary medicine library. Voluntary statements on the questionnaire such as the following support this further: "The veterinary library in general does not duplicate periodicals already available in the main library. The majority of periodicals in the field of general science, biology, bacteriology, anatomy, physiology, biochemistry, etc., are kept in the main library."

This survey obviously does not answer all specific questions and was not intended to approach definitiveness. But the general guideline which it suggests does give us at Kansas State University helpful information for planning for the future. 